\title{
Mechanical Properties Of Sunflower Seeds
}

\author{
Bo Wang, Lihua ZhangC, Linglin Zhang \\ College of mechanical and electrical engineering, Sichuan Agricultural University \\ Ya'an, China
}

\begin{abstract}
Sunflower seed has attracted the researchers' attention because its' high nutrition oil. Shell breaking mechanics characteristics test and analysis of sunflower seeds, as to provide a theoretical basis for the pressing equipment and research on sunflower seeds. Through single factor test and orthogonal test of three factors and three levels, the loading direction,moisture content and loading rate as variable; the shell breaking force,breaking deformation with energy consumption are response index. By compared the significance and differences of the data results, finding the best loading mode of sunflower seeds.By single factor test, it was found that shell breaking force along the $Y$ axial are minimum; breaking deformation and energy consumption along the $Z$ axial are minimum..By orthogonal test, the linear models are established which are as follows: $F=-0.29 \mathrm{v}-1.69 \mathrm{c}-17.1 \mathrm{~d}+138.4, \quad \mathrm{~S}=-0.046 \mathrm{v}+0.011 \mathrm{c}$ $0.29 \mathrm{~d}+2.043, \mathrm{E}=-\mathbf{0 . 4 3 v}-1.09 \mathrm{c}-21.1 \mathrm{~d}+112.7$. These models can well describe the loading process of the sunflower seeds. The mechanics characteristic test of sunflower seeds provides a necessary mechanical basis for designing and researching of the related machinery and equipment.
\end{abstract}

Keywords-sunflower seed; shell breaking force; shell breaking deformation; shell breaking energy; linear regression

\section{INTRODUCTION}

Sunflower seed, which is the fruit of sunflower, one of important oil crops because it contains large amounts of high quality oil[1]. Sunflower seed resources are rich, the annual output of China is more than 1,250,000 tons

[2].Sunflower seeds contain protein $21 \% \sim 30 \%$, grease $28 \% \sim 32 \%$, better than animal fats and vegetable oils.

Sunflower seeds also contain abundant VE 、 VB6, carotene, which could enhance the health of the human body. It also contains carbohydrAtes (digestible) $12.6 \%$, cellulose $2.7 \%$, ash $4.4 \%$, and abundant trace elements, vitamin [3].

During the past few decades, many scholars have done research on sunflower seeds processing, such as isolation and characterization of sunflower protein[4],mathematical model for pressing of sunflower seeds[5], and the digestibility of sunflower meal effect on rabbits[6], and simultaneous extraction of oil and water-soluble pase from sunflower seeds with subcritical water[7]. However, theoretical studies on the mechanical properties of sunflower seeds are very rare, R.Khodabakhshian did a compression test[7], but the amount of data in their test is very small, moisture content is less than $15 \%$, and did not consider the impact of load speed.So,study on the mechanical characteristics of sunflower seeds is necessary.

\section{MATERIALS AND METHODS}

\section{A. Materials and Equipment}

The experimental materials used fresh sunflower seeds in Ya'an city, Sichuan province,no pests, shell rupture injury. Their common characteristics are: the whole is a long elliptic in somber black,both sides have crack, approximation on shell symmetry.

Testing equipment mainly contains compression tester, WD-W precise micro control electronic universal testing machine(Ji'nan Fangchen Instrument Equipment Co, Ltd,.Ji'nan,China ). Electronic balance(Shanghai Ohaus Corporation.Shanghai,China).Type DHG9146A electric constant temperature drying oven (Shanghai Suda Experimental Instrument Co,. Ltd, Shanghai, China).

\section{B. Methods}

The test adopts horizontal ( $\mathrm{X}$ direction), on the side ( $\mathrm{Y}$ direction), stood on ( $Z$ direction) three different modes of loading directions. To make it stable, we use little seconds quick drying glue.The computer display shell breaking force, deformation, displacement and other parameters during the tests. The data start showing when the disk access to the material's surface.The force drop when the sunflower seeds' shell breaking and the computer stop recording data, then display the data on the screen.

\section{Data Measurement and Parameter Calculation}

There are three responses in the test: the shell breaking force $\mathrm{F}$, deformation S, shell breaking energy E. Among them $\mathrm{F}$ and $\mathrm{S}$ are recorded by the computer.The calculation methods of $E$ is as following:

$$
E=\frac{1}{2} \sum_{i=1}^{n}\left[\left(F_{i}+F_{i+1}\right)\left(S_{i+1}-S_{i}\right)\right]
$$

Because the curves of the compression process close the graph of proportional function, So the calculation of shell breaking energy can be simplified as:

$$
E=\int_{0}^{S} F(S) d S \approx \frac{1}{2} F \times S
$$

Referencing GB/T 5497-1985[4] on the seeds moisture content determination and related literature[5] The experiment used $105^{\circ} \mathrm{C}$ constant weight method to test the dry mass of sunflower seeds:

$$
M_{e}=\frac{m-m_{0}}{m_{0}} \times 100 \%
$$


Where, $M_{e}$ is the wet basis moisture content (\%), $\mathrm{m}$ is the initial mass $(\mathrm{g})$, and $\mathrm{m} 0$ is the mass of absolute dry $(\mathrm{g})$;

\section{RESULTS AND ANALYSIS}

\section{A. Single factor test}

Through single factor analysis of variance of the results, and fitting the curve with toolbox of cftool by using Matlab.

\section{B. Significance analysis}

As shown in table 1, at the loading rate of $15 \mathrm{~mm} / \mathrm{min}$ ,the moisture content showed a weak significant effect on the deformation when loading on the Y direction, on the rest of the response is very significant. When the moisture content is $16.36 \%$, the loading speed on the deformation under the direction of $\mathrm{X}$ is very significant, the remaining responds under $\mathrm{X}$ direction is not significant; Shell breaking force and energy is very significant under the direction of $\mathrm{Y}$, but on the deformation is not obvious, the energy consumption under $\mathrm{Z}$ direction is not significant, for the rest of the response is very significant.

\section{Mechanical properties of sunflower seeds with}

\section{different moisture content \& loading speed}

As shown in Fig.1,as the water contend increase, sunflower seed shell fiber and grain moisture content rise, sunflower seed shell and seeds integral is bigger, seed and shell joint, increased breaking force.The sunflower large gap between the housing and the grain in the $\mathrm{Y}, \mathrm{Z}$ directions, with increasing moisture content, fiber becomes fluffy, broken shell force drops. As the moisture content increased gradually soft the shell, but the moisture content is further increase, the larger and thicker plastic shell becomes stronger, broken shell deformation becomes larger.

As shown in fig.5, when loading under the $\mathrm{X}$ direction, loading speed effect on the force is not significant, but the overall force is greater than the broken shell under $Y, Z$ directions. When loading under the $Z$ direction, with the loading speed increase, two peaks occur at the loading speeds of $15 \mathrm{~mm} / \mathrm{min}$ and $30 \mathrm{~mm} / \mathrm{min}$. And in the $Y$ direction with the loading speed increase, broken shell force decrease.
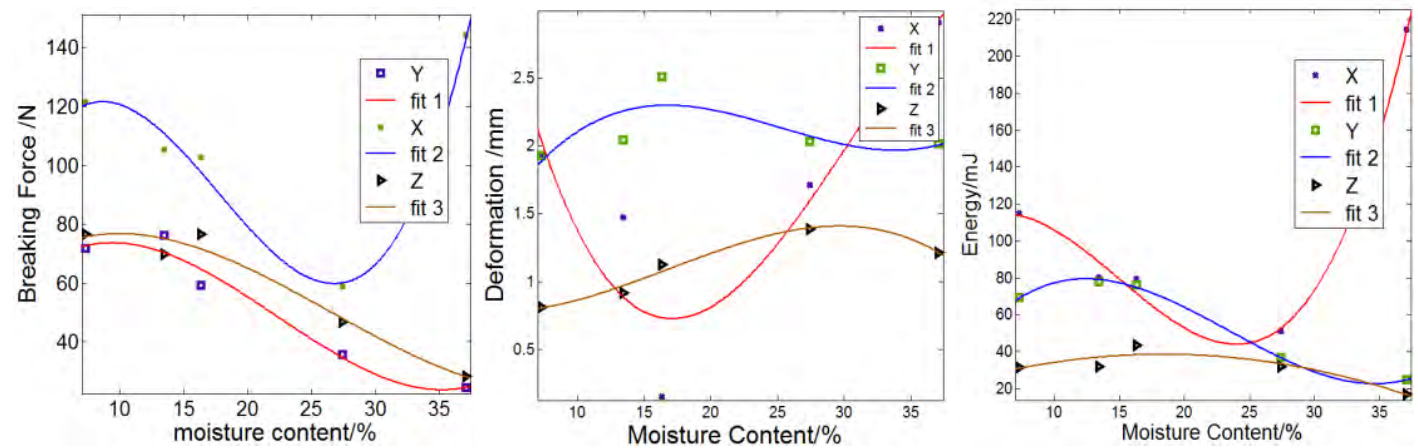

Figure 1. Sunflower mechanical properties under different moisture content
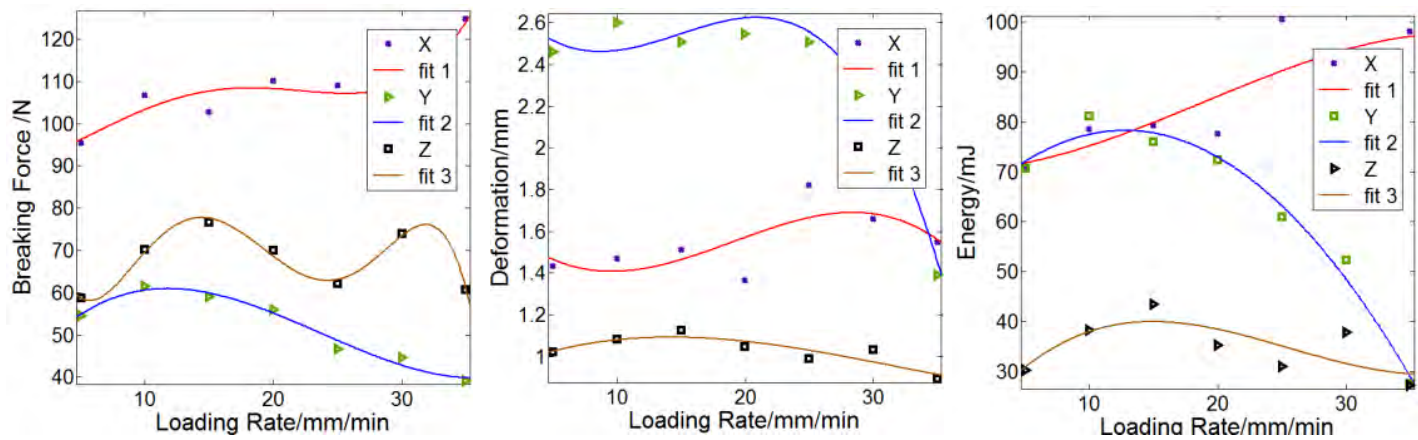

Figure 2. Sunflower mechanical properties under different loading rate

\section{Orthogonal test}

Using the L9(34) orthogonal test table,each of the response index was repeated 10 times and take average value.Orthogonal test results are shown in Table2.

The three variables that affect the performance of broken shell, respectively, force, force, deformation, energy multivariate linear regression. As shown in table 3 can get broken shell performance linear regression model with three variables for(When placed horizontally in this article take $\mathrm{D}=1$, when on the side take $\mathrm{D}=2$, stand up when taking $\mathrm{D}=3$ ): 


$$
\begin{aligned}
& F=-.029 V-1.69 C-1.71 D+138.4 \\
& S=-0.046 V+0.011 C-0.29 D+2.043 \\
& E=-0.43 V-1.09 C-21.1 D+112.7
\end{aligned}
$$

\section{E. Index test}

As shown in table 4.Three variables on the performance of the broken shell multivariate linear regression model significant at the 0.05 level.Table 4 shows $\mathrm{p}<0.05$, so the above model establishment.

\section{CONCLUSIONS}

Single factor tests showed: under various conditions, loaded from three directions $\mathrm{X}, \mathrm{Y}, \mathrm{Z}$, when loaded to break the shell along the $\mathrm{Y}$ gets the minimum force, while under the $\mathrm{Z}$ direction loading deformation and energy consumption are minimized. When loading at the speed of $15 \mathrm{~mm} / \mathrm{min}$ under all directions, the moisture content effect on the force and, energy consumption is very significant,For $\mathrm{Y}$ direction of energy consumption, the moisture content shows a weak significance on the deformation.

At moisture content of $16.36 \%$, the loading speed effect on the force of $\mathrm{Y}$ direction is very significant; on the force under the $Z$ direction, deformation under the direction of $\mathrm{X}$ and $\mathrm{Y}$, and energy consumption under $\mathrm{Y}, \mathrm{Z}$ directions performance a weak significance.On the force under $\mathrm{X}$ direction, the deformation under the $\mathrm{Z}$ direction, energy consumption under $\mathrm{X}$ direction performance no significance. Orthogonal test results showed that: broken shell strength, broken shell deformation, broken shell linear model with variable energy are: $F=-0.29 v-1.69 c-17.1 d+138.4$,

$S=-0.046 v+0.011 c-0.29 d+2.043$

$E=-0.43 v-1.09 c-21.1 d+112.7$.

TABLE I. RESULTS OF ORTHOGONAL TEST

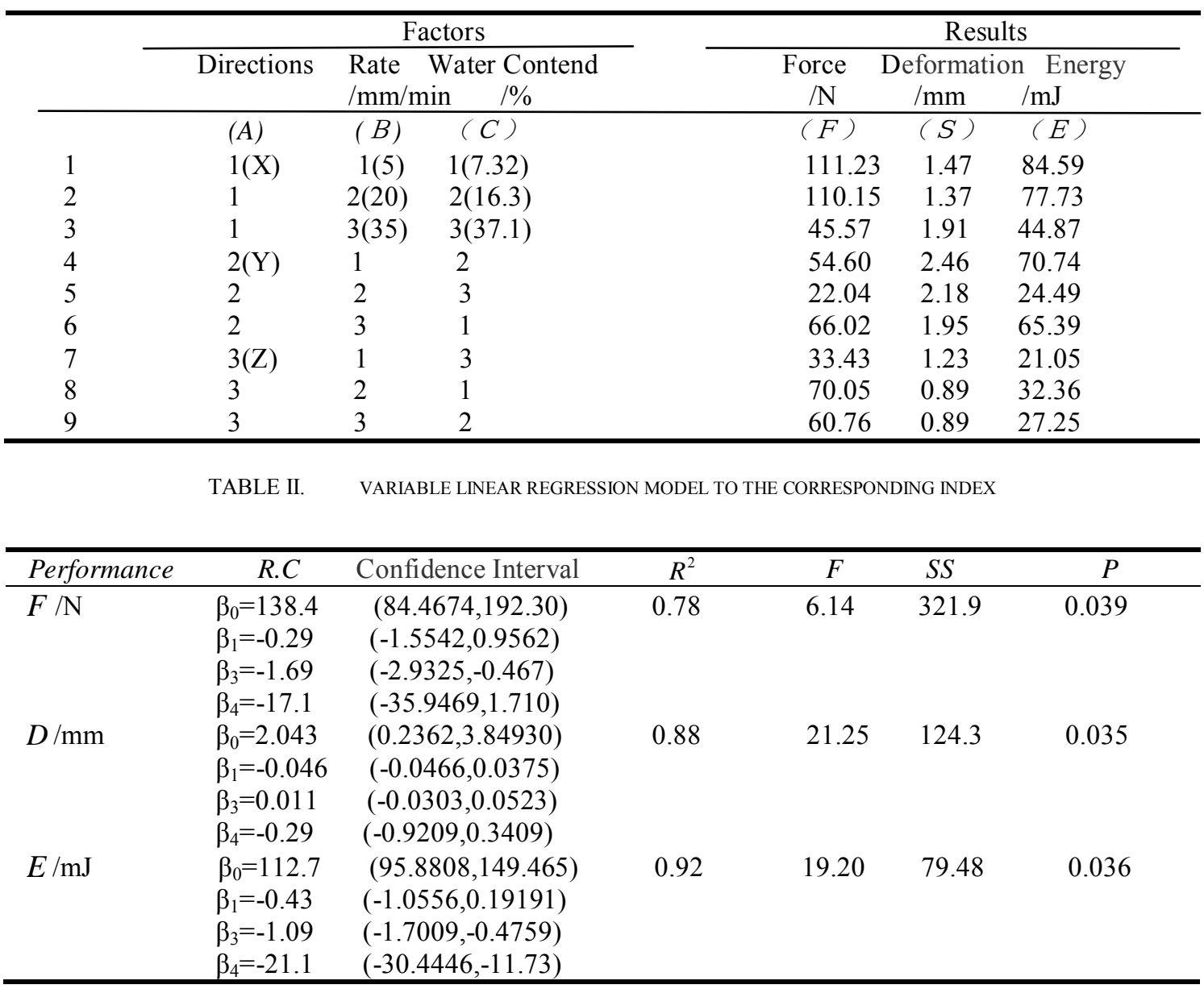


TABLE III. VARIABLES TO TEST THE CORRESPONDING INDEX OF THE LINEAR REGRESSION EQUATION

\begin{tabular}{lllllllc}
\hline Performance & Source & SS & df & MS & F & Prob $>\mathrm{F}$ & Significance \\
\hline$F / \mathrm{N}$ & columns & 75338 & 8 & 9417 & 22.09 & 0 & $* * *$ \\
& error & 34537 & 81 & 426.3 & & & \\
& total & 109875 & 89 & & & & $* * *$ \\
$D / \mathrm{mm}$ & columns & 25.02 & 8 & 3.12 & 14.44 & 0 & \\
& error & 17.54 & 81 & 0.21 & & & $* * *$ \\
& total & 42.56 & 89 & & & & \\
& columns & 49755 & 8 & 6219 & 9.55 & 0 & \\
& error & 52735 & 81 & 651.1 & & & \\
& total & 102490 & 89 & & & \\
& & Note: *** to represent significant difference at 0.05 level
\end{tabular}

\section{ACKNOWLEDGEMENTS}

Corresponding Author: Lihua Zhang, Professor,Master Instructor. Research Direction: Machine and equipment for agriculture products processing. Email: zhanglihua69@126.com.

\section{REFERENCE}

[1] R.K. Gupta, G. Arora, R. Sharma. Acrodynamic propcritics of sunflower seed(Hclianthus annuus L) J .Journal of Food Engineering,2007,79:899-904

[2] R. H. He, QJ Zhai, HS Zhong, et al.Study on Refluxing Microwave-Assisted Extraction of Chlorogenic Acid from Sunflower Seed Meal J . Journal of the Chinese Cereals and Oils Association, 2012,27 (9): 107-111.

[3] L. Wang, H. Y. Zhang, X. L Bai, et al. New Exploitation of Resources of Sunflower Seed in Food Industry. J.Food Science and Technology. 2007,32(10):7-9
[4] J. Ren, X. Q. Zheng, X. L. Liu, et al.Isolation and Characterization of Sunflower Protein .J. Journal of the Chinese Cereals and Oils Association, 2008, 23(3):100-103.

[5] Y. X. Zhang, X.L Zheng, GX Lin Plasticity Model for Pressing of Sunflower Seeds .J. Transactions of the Chinese Society of Agricultural Machinery, 2009, 7:138-142.

[6] A. C. Firlan , H. G. Faria , C.Scapinellp, etal.The digestibility of sunflower meal effect on the performance of growing rabbits[J].Acta Scientiarum: Animal Sciences,2001,23(4):10231027.

[7] M. Ravber., Z. Knez., M. Skerget. simultaneous extraction of oil and water-soluble pase from sunflower seeds with subcritical water.J. Food Chem.2014.pp316-323.

[8] R. Khodabakshian, B. Emadi, M. H. Abbaspour Fard,et al. Mechanical Properties of Sunflower Seed and Its Kernel, Azargol Variety as a Case Study, Under Compressive Loading, Journal of Agricultural Science and Technology. 2010,2:34-40.

[9] Inspection of grain and oilseeds Methods for determination of moisture content. Z .1986.7.1. [10] Z. H. Ma, L. H. Zhang, L. Xia Experiment of Mechanical Characteristics of Jatropha Seeds J.Journal of Southwest Agricultural University. 2012,3:131-137. 